\title{
O Estudante de Medicina no Conselho Municipal de Saúde: Construindo a Responsabilidade Social
}

\section{PALAVRAS-CHAVE: \\ - Estudantes de Medicina; \\ - Conselhos de Saúde; \\ - Responsabilidade Social.}

\section{KEY WORDS:}

- Student, Medical;

- Health Planning Councils;

- Social Responsibility.

Recebido em: 04/10/2006

Reencaminhado em:13/08/2007

Aprovado em:14/02/2008

\section{The Medical Student in the Municipal Health Council: Constructing Social Responsibility}

Ione Morita ${ }^{I}$

Margareth Aparecida Santini de Almeida

\begin{abstract}
RESUMO
As escolas médicas vêm promovendo reformas curriculares, buscando novos cenários de ensino e aprendizagem, respondendo tanto aos princípios do Sistema Único de Saúde quanto às Diretrizes Curriculares, que se complementam no sentido de se dispor de profissionais críticos na área da saúde. Este artigo descreve as atividades de extensão desenvolvidas por alunos no Conselho Municipal de Saúde (CMS) de Botucatu (SP) no período de 2000-2005 e sua percepção sobre essas atividades em sua formação. Os estudantes freqüentaram as reuniões do CMS, leram as atas, entrevistaram os conselheiros, participaram de encontros de saúde promovidos para formar conselheiros de saúde e elaboraram um relatório de avaliação. Os alunos foram unânimes em valorizar esse contato e, por meio dessa experiência, desenvolveram a capacidade reflexiva, parte da construção da responsabilidade social. Cumpriu-se, também, a articulação entre ensino e demandas sociais, papel esperado da universidade, contribuindo para uma mudança das pessoas envolvidas.
\end{abstract}

\section{ABSTRACT}

The formational function of the university must establish a relationship with the society to be able to respond to its needs. In this connection, medical schools have been promoting curricular reforms seeking for new teaching and learning scenarios responding as much to the principles of the Brazilian Health System as to the Curricular Guidelines, complementing each other in the sense of preparing critical professionals for the health area. The objective of this paper was to describe the extra-curricular activities performed by students in the Municipal Health Council of Botucatu in the period 2000-2005, and their perception of the role of these activities in their formation. With regard to the methodology, the students participated in MHC meetings, red the records, interviewed the members of the council, participated in encounters held for preparing health councilors and elaborated an evaluative report. The students were unanimous in appreciating this experience, which allowed them to develop reflective capacity, part of the construction of social responsibility. The experience also contributed to the articulation of teaching and social demands, the expected role of the university, promoting a change in the persons involved. 


\section{INTRODUÇÃO}

A questão do desenvolvimento da sociedade passa pela formação do homem. Neste artigo, considera-se a função formadora da universidade para esse processo. No entanto, reconhece-se, como Kourganoff ${ }^{1}$, que o papel da universidade não se restringe ao ensino, à formação, mas também promove o progresso do conhecimento por meio da pesquisa e extensão. Neste sentido, a relação universidade-sociedade torna-se outro campo importante de reflexão e atuação.

Uma das grandes preocupações na formação dos estudantes universitários é o quanto a universidade deve se adequar às demandas do mercado e/ou induzir demandas novas. Segundo Roca e $\mathrm{Canal}^{2}$, se a universidade se voltar prioritariamente ao mercado, vai interessar muito mais a ela que seus formandos dominem determinadas técnicas do que desenvolvam a reflexão e o pensamento; que se acomodem às normas sociais do que desenvolvam uma resistência crítica; e se importem mais com o mérito de alguns do que com a justiça para todos. Neste último caso, conforme os autores, o que disciplina o estudo e o esforço do estudante é a obtenção do título acadêmico. No entanto, se mantiver contato com as demandas da sociedade, o esforço da universidade vai desde enfrentar a pressão do mercado, à busca de sentido e compromissos que exigem responsabilidades que podem não atender às razões competitivas estabelecidas pelo mercado. Fica claro que existem diferentes missões que a universidade deve atender nas áreas de pesquisa, econômica e social, cujas razões são muito diversas, mas cuja execução não precisa ser contraditória, e, como Kourganoff ${ }^{1}$ sublinhou, algumas vezes podem até ser convergentes.

No caso da formação dos médicos, verificamos que o grande avanço científico-tecnológico acaba por estabelecer um paradoxo quando a relação médico-paciente, ao se focar na doença, se distancia das dimensões psicológicas e sociais ${ }^{3}$ que recobrem o ser humano. Numa formação histórica com grande capital tecnológico, a ação pedagógica tende a reproduzir o sistema cultural característico dessa formação social, colocando em posição dominante o que se transformou num "arbitrário cultural", como definiram Bourdieu e Passeron". Este "arbitrário cultural" aparece, por exemplo, na valorização cultural que hierarquiza as especialidades médicas, apreendida por todo estudante de graduação, e nas relações de força entre os departamentos das escolas. Como alguns autores têm $\operatorname{mostrado}^{5}$, o processo de formação médica valoriza pouco a formação generalista, e, com o desenvolvimento das especialidades médicas incorporadas à graduação, multiplicaram-se as disciplinas, colocando em discussão qual e quanto seria o conteúdo para seis anos de curso. Esses aspectos estão na base do poder de instauração de uma comunicação e uma diretriz pedagógica.

Em face desses aspectos, as escolas médicas vêm promovendo reformas curriculares ao longo das últimas décadas, para articular mudanças no ensino. Segundo Cyrino e Rizzato ${ }^{6}$, nos anos 1990, as escolas médicas da América Latina propuseram um ensino que tomasse como objeto as necessidades sociais de saúde e buscasse novos cenários de ensino e aprendizagem, além de uma articulação entre os diferentes níveis de atenção, integrados aos serviços de saúde.

Em 2001, no Brasil, o Ministério da Educação implantou as novas Diretrizes Curriculares ${ }^{7}$ para os cursos de graduação em Medicina. Entre seus princípios destacamos os seguintes artigos e itens:

\section{Artigo $5^{\circ}$}

A formação do médico tem por objetivo dotar o profissional dos conhecimentos requeridos para o exercício das seguintes competências e habilidades específicas:

XX. Ter visão do papel social do médico e disposição para atuar em atividades de política e de planejamento em saúde.

\section{Artigo $12^{\circ}$}

A estrutura do Curso de Graduação em Medicina deve:

VI. Utilizar diferentes cenários de ensino-aprendizagem permitindo ao aluno conhecer e vivenciar situações variadas de vida, da organização da prática e do trabalho em equipe multiprofissional.

Reconhecer a necessidade de aprendizagem em diferentes cenários, vivenciando diferentes realidades sociais, é também assumir a complexidade da determinação da saúde da população, conforme exposto no artigo $3^{\circ}$ da Lei 8.080 (BRASIL, $2001)^{8}$, que dispõe sobre as condições para a promoção, proteção e recuperação da saúde, entre outros aspectos:

\section{Artigo $3^{\circ}$}

A saúde tem como fatores determinantes e condicionantes, entre outros, a alimentação, a moradia, o saneamento básico, o meio ambiente, o trabalho, a renda, a educação, o transporte, o lazer e o acesso aos bens e serviços essenciais; os níveis de saúde da população expressam a organização social e econômica do País. (BRASIL, 2001) ${ }^{8}$ 
De outro lado, considerar o papel social e desenvolver atividades de política e planejamento em saúde é responder à necessidade dos Conselhos de Saúde quanto à formulação de estratégias, entre outros aspectos, conforme segue:

$\S 2^{\circ}$ - O Conselho de Saúde, em caráter permanente e deliberativo, órgão colegiado composto por representantes do governo, prestadores de serviço, profissionais de saúde e usuários, atua na formulação de estratégias e no controle da execução da política de saúde na instância correspondente, inclusive nos aspectos econômicos e financeiros, cujas decisões serão homologadas pelo chefe do poder legalmente constituído em cada esfera do governo. (BRASIL, 2001) ${ }^{8}$

Ao se institucionalizar a participação do Estado, colocaram-se lado a lado gestores, profissionais da área da saúde e lideranças da sociedade civil organizada. A competência de um conselho de saúde é examinar e aprovar as diretrizes da política de saúde e formular estratégias que possam aperfeiçoála e corrigir rumos ${ }^{9,10}$. Esta situação pressupõe a necessidade de construir uma massa de conselheiros críticos e conscientes desse papel. E a universidade terá um papel marcante nessa situação, caso se integre com outros atores sociais.

Por outro lado, voltando a atenção ao papel original da universidade como centro do conhecimento, vemos, por sua história, que ela já nasceu separada da sociedade civil - elitista, própria das classes dominantes, lócus de erudição, em oposição ao conhecimento vulgar, empírico e não erudito. Conforme Iyda ${ }^{11}$, essa posição se manteve até meados do século XX, quando a sociedade mais democrática que surgiu no pósguerra começou a questionar a não resolução de problemáticas sociais. Nesse quadro, emerge o projeto de extensão universitária como uma resposta, embora possa ser uma resposta equivocada, segundo Chauí1 ${ }^{12}$, conforme o enfoque adotado.

Como Freire ${ }^{13}$ demonstrou, há um sentido implícito na palavra extensão, relacionado a uma ação de levar, transferir "algo" - conhecimento, neste caso - para alguém que não tem, numa posição hierárquica em que nada se mudava do enfoque que se criticava. Mas, como destacado por $\operatorname{Iyda}^{11}$ em relação a Freire $^{13}$, o autor mostrava que conhecimento não se estende porque constitui uma relação entre sujeitos diferentes e desiguais.

Assim é que uma prática inovadora e desafiadora para a universidade se volta para sua capacidade de integrar os três pilares que a sustentam - ensino, pesquisa e extensão - não apenas no sentido do avanço científico-tecnológico, mas também na construção de um profissional crítico, que se abre para outros saberes e práticas, numa relação dialética que encontre respostas para as necessidades sociais. Com a abertura de novos cenários de ensino por meio de projetos pedagógicos que se inter-relacionam com a rede de serviços de saúde pública, tem-se um pano de fundo para uma experiência de aprendizado que desenvolva a responsabilidade social.

Considerando que a distância social desenvolve o desconhecimento do outro, elaborou-se um projeto na área de extensão universitária que propiciasse, desde cedo, o contato entre futuros profissionais médicos com lideranças populares na área da saúde e demais segmentos participantes da formulação da política de saúde local. Partiu-se do pressuposto de que o controle social na saúde só seria efetivo se todas as partes envolvidas - "comunidade", profissionais de saúde e governo - passassem a se conhecer e a compartilhar uma visão de mundo, e superassem, entre outros aspectos, barreiras sociais e culturais.

Outro pressuposto está relacionado à formação precoce de um médico com uma visão crítica da realidade econômica, política e social, mediante a observação direta e participante nos fóruns de decisão da área da saúde, de modo que se cumprisse o preconizado no item $X X$ do artigo $5^{\circ}$ das Diretrizes mencionadas. Considerou-se, também, que novos enfoques de aprendizagem requerem novos enfoques de ensino. A experiência a ser relatada deve ser entendida não como uma "coisa" rígida e fechada, mas como algo vivo e, portanto, que cresce. A reflexão sobre essa experiência representa uma oportunidade de contribuir para um novo pacto colocado pelas diretrizes da saúde e da educação ${ }^{14}$.

O objetivo deste artigo é descrever as atividades de extensão desenvolvidas por graduandos de Medicina no Conselho Municipal de Saúde de Botucatu de 2000 a 2005, e a percepção deles sobre essas atividades em sua formação.

\section{PROCESSO METODOLÓGICO}

No final dos anos 1990, a Universidade Estadual Paulista Júlio de Mesquita Filho intensificou uma linha de crédito, com recursos da Pró-Reitoria de Extensão (Proex), que incentivava a participação social de seus alunos por meio de bolsas de incentivo técnico-acadêmico. O projeto "Conselheiros municipais de saúde: problema ou solução?", encaminhado em 1999 e aprovado no ano 2000, deu início a essa experiência em educação na Faculdade de Medicina de Botucatu.

O município de Botucatu, na região central do estado de São Paulo, contava com 108.307 habitantes no ano 2000. O primeiro Conselho Municipal de Saúde (CMS) tomou posse em 1992, tendo havido mudanças em julho de 1994, em janeiro de 1997, em agosto de 1999 e em abril de 2003. 
De 2000 a 2005, contou-se com um ou dois alunos bolsistas por ano, num total de seis, que participaram das reuniões do CMS, leram as atas para entender sua dinâmica de funcionamento e entrevistaram os conselheiros. A partir dessas entrevistas, observaram, entre vários aspectos, a necessidade de treinamentos dos conselheiros, e desenvolveram boletins informativos. Nessas entrevistas, tanto titulares quanto suplentes de duas gestões foram procurados. Os alunos também participaram de encontros populares de saúde e oficinas realizadas para formar conselheiros de saúde. No final de cada ano, individualmente, elaboraram um relatório de avaliação.

\section{RESULTADOS E DISCUSSÃO}

Nas atividades de extensão, os alunos participaram dos encontros e oficinas para formação de conselheiros, e essa integração possibilitou uma parceria para aquisição e troca de conhecimentos sobre o Sistema Único de Saúde (SUS), e suas implicações. Os estudantes foram preparados sobre aspectos selecionados das dificuldades dos conselheiros, levantados nas entrevistas, e colaboraram nas discussões. Outro resultado dessa interação foi a confecção de material informativo sobre o Conselho Municipal de Saúde. Teve-se o cuidado de apresentar um rascunho a algumas lideranças populares, garantindo-se, além do compartilhamento de idéias, a certeza de que a população que utiliza os serviços públicos de saúde compreenderia o texto. A distribuição desse boletim atingiu os objetivos esperados, pois constantemente são solicitadas mais cópias.

As atividades de encontros, reuniões e produção de boletins foram subsidiadas pelo aprofundamento da análise conceitual sobre participação e controle, construindo-se um conhecimento sobre o que é e poderia ser o controle social, seus caminhos e descaminhos.

Quanto à percepção dos alunos sobre a influência dessas atividades de extensão em sua formação, as avaliações individuais são expressivas:

Avalio que esse trabalho de extensão universitária contribuiu de diversas formas para minha formação [...] por fazer com que eu entrasse em contato com a comunidade e com as instituições de saúde através do trabalho de campo realizado durante mais de seis meses, e composto pelas entrevistas feitas com 24 conselheiros titulares, realizadas, em sua maioria, no próprio local de trabalho dessas pessoas. Isso possibilitou o conhecimento de uma realidade muito diferente da minha e uma troca de conhecimento e informações muito grande, já que, ao me apresentar como aluna graduanda da Faculdade de Medicina, alguns faziam perguntas sobre a organização e estrutura da faculdade, sobre o engajamento dos alunos em projetos comunitários como esse. (DB., bolsista).

Pude ter maior integração com a comunidade, saindo da esfera acadêmica e verificando o funcionamento prático do sistema de saúde do município, tendo uma visão crítica do trabalho da Secretaria Municipal de Saúde. O contato com os conselheiros foi de grande valor, na medida em que pude orientá-los a otimizar o acesso à saúde do município. (CAPB, bolsista).

Existem conselhos que foram criados apenas para receber recursos do governo federal sem a preocupação de garantir a representatividade. Neste caso, os conselheiros são dependentes e as pautas atendem aos interesses do governo e seus pares, e acabam por legitimar políticas que vão contra a real necessidade da população. Procuramos, com nossa atuação, desenvolver um pouco da educação enquanto ação cultural para a liberdade conforme proposta de Paulo Freire, e o ensino médico, ainda que por um projeto de extensão, como forma particular de realização do processo educacional, que ainda tem algo a dizer e fazer no que tange à constituição de sujeitos sociais. (CNB, bolsista)

Foi possível através dessa experiência ampliar os horizontes como estudante de Medicina [...] percebendo uma outra realidade que envolve problemas locais de usuários, políticas de gastos na área da saúde, articulações de cada integrante do Conselho na busca de interesses pessoais ou do grupo a que pertence. Entender a importância da representatividade dos usuários na efetivação do controle social e de estar presente em um espaço de decisão política representando os estudantes corresponde a uma aprendizagem formativa que ultrapassa os limites de ensino do curso de graduação da Faculdade de Medicina de Botucatu. (BMBL, bolsista).

Desde o início de nossas atividades no projeto, temos acompanhado as reuniões ordinárias e 
extraordinárias que ocorrem em um anexo da Secretaria Municipal de Saúde [...] fomos desenvolvendo um olhar crítico capaz de interpretar e avaliar as diversas discussões que ocorrem dentro do Conselho [...] um questionário aplicado aos conselheiros que nos possibilitou um melhor conhecimento dos representantes de cada segmento social e o que estes esperam e fazem dentro do Conselho. A partir da vivência dessas reuniões, com a análise das atas das mesmas e de posse do referido questionário, pudemos obter uma rica fonte de dados para o aprofundamento de nosso estudo. Esse estudo analisou a participação dos diferentes segmentos da sociedade representados no CMS e a representatividade desses segmentos na tomada de diretrizes na política de saúde local. Para esse propósito, o estudo avaliou, entre outras coisas, a distribuição por sexo entre os conselheiros, suas freqüências nas reuniões e as respostas que o Conselho apresenta a cada segmento social para as reivindicações levadas por seus respectivos representantes (conselheiros). (JFCG e BPM, bolsistas).

Chama-se a atenção, assim, para um aspecto destacado pelos alunos em relação ao contato com a sociedade mais ampla: se durante o curso médico se aprende a ver as pessoas como "pacientes", o projeto permitiu que as conhecessem como "atuantes", num jogo de palavras carregado de significados.

\section{À GUISA DE CONCLUSÃO}

Tratando-se de um processo, a participação e a responsabilidade social que estão em foco neste trabalho não se encerram. Ao contrário, com avanços e recuos, o movimento social das mais diversas categorias - estudantes, trabalhadores, grupos minoritários, grupos políticos e ideológicos - tem tido conquistas e revezes.

Uma das grandes dificuldades na análise de um conselho de saúde é que sua implantação é um processo em constante aperfeiçoamento, portanto, em mudança. O conselho é um espaço onde os acontecimentos na área da saúde pública se encontram, despertam paixões, na defesa de interesses próprios ou de grupos, e "confundem a esperança fugaz"15. Considerando os avanços, abriu-se um espaço que permitiu a aproximação entre diferentes segmentos e instituições envolvidos com a saúde.

Na maior parte de todas as experiências, o fundamental é a relação pessoal ou entre pessoas e grupos. Nessa troca, a expe- riência fornece "o material mais adequado ao desenvolvimento das capacidades generalizadas do pensamento"14. Portanto, aproximar futuros profissionais de saúde da comunidade, dos representantes governamentais e dos profissionais da saúde, e participar de reuniões do conselho municipal de saúde, de encontros de voluntários em apoio aos conselheiros permitiriam a todos os envolvidos o desenvolvimento da capacidade reflexiva. O aumento desta capacidade permitiria um desenvolvimento inter-relacionado entre conhecimento e controle, obtendo-se, entre outros aspectos, o controle da sociedade sobre o Estado, proposta do SUS. Não é uma tarefa simples, cujos resultados se possam medir e quantificar, mas, trata-se de contribuir para o aperfeiçoamento da cidadania, ainda que em pequena escala.

Em relação à articulação entre ensino e demandas sociais, papel esperado da universidade, a discussão com os alunos de temas sobre controle e participação social - que durante os cursos regulares não se tem como aprofundar, mas que neste projeto foram enfocados sob uma nova perspectiva, o da vivência - dinamizou o processo de aprendizagem. A partir do enfoque teórico sobre as determinações que incidem sobre o controle social, aqui entendido como o controle da sociedade sobre o Estado, percebeu-se, na prática, como ela vem ocorrendo e procurou-se contribuir para uma mudança, embora aparentemente parecesse tão pouco.

Unir a teoria acadêmica à prática dos conselheiros de saúde deverá resultar numa nova práxis de todos os atores envolvidos, e este é um ideal que não se perde de vista, embora o processo seja lento.

\section{REFERÊNCIAS}

1. Kourganoff W. A face oculta da universidade. São Paulo: Ed. da Universidade Estadual Paulista; 1990.

2. Roca JG, Canal GM. Jóvenes, Universidad y compromiso social. Una experiencia de inserción comunitaria. Madrid: Narcea; 2002.

3. Trindade EMV, Almeida HO, Novaes MRCG, Versiane ER. Resgatando a dimensão subjetiva e biopsicossocial da prática médica com estudantes de medicina: relato de caso. Rev bras educ med. 2005;29(1):48-50.

4. Bourdieu P, Passeron JC. A reprodução. Elementos para uma teoria do sistema de ensino. Rio de Janeiro: F. Alves; 1975.

5. Ferreira RC, Silva RF, Aguer CB. Formação do profissional médico: a aprendizagem na Atenção Básica de Saúde. Rev bras educ med. 2007;31(1):52-59.

6. Cyrino EG, Rizzato ABP. Contribuição à mudança curricular na graduação da Faculdade de Medicina de Botucatu. Rev bras saúde matern infant. 2004;4: 59-69. 
7. Brasil. Ministério da Educação. Conselho Nacional de Educação. Diretrizes Curriculares Nacionais do Curso de Graduação em Medicina [on-line]; 2001. [capturado 28 ago. 2006]. Disponível em: <http://www.abem-educmed. org.br/diretrizes_curriculares.htm\#>.

8. Brasil. Ministério da Saúde. Gestão Municipal de Saúde: leis, normas e portarias atuais. Rio de Janeiro: Ministério da Saúde; 2001.

9. Morita I, Guimarães JFC, Muzio BPD. A participação de Conselheiros Municipais de Saúde: solução que se transformou em problema? Saúde Soc. 2006;15:49-57.

10. Morita I, Concone MHVB. Conselho e conselheiros municipais de saúde: que trama é esta? Ciênc. soc. Unisinos. 2002;38:147-167.

11. Iyda M. Universidade, extensão e sociedade: algumas reflexões. In: Cyrino A P, Magaldi C. (org.). Saúde e comunidade: 30 anos de experiência de extensão universitária em Saúde Coletiva. Botucatu: Cultura Acadêmica; Faculdade de Medicina de Botucatu, Universidade Estadual Paulista; 2002. p.221-226.
12. Chauí MS. A Universidade hoje. Praga: estudos marxistas. São Paulo: Hucitec; 1998. v. 6. p. 23-32.

13. Freire P. Extensão ou comunicação? 10. ed. Rio de Janeiro: Paz e Terra; 1977.

14. Dewey J. Como pensamos: como se relaciona o pensamento reflexivo com o processo educativo: uma reexposição. 4. ed. São Paulo: Nacional; 1979.

15. Balandier G. O dédalo: para finalizar o século XX. Rio de Janeiro: Bertrand Brasil; 1999.

\section{CONFLITOS DE INTERESSE}

Declarou não haver.

\section{ENDEREÇO PARA CORRESPONDÊNCIA}

Ione Morita

Caixa Postal 549

Botucatu / SP

CEP. 18618-970

E-mail: imorita@fmb.unesp.br 